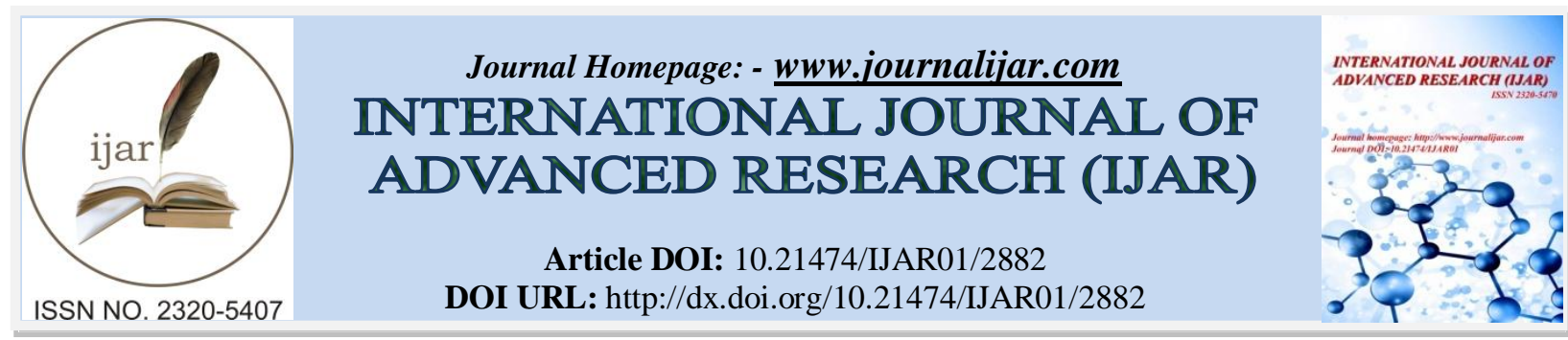

RESEARCH ARTICLE

\title{
LASER 805NM EFFECTS ON BACTERIAL GENETIC AND SENSITIVITY TOWARD ANTIBIOTICS.
}

\section{Saifadin Khder Mustafa ${ }^{1}$, Abdulkarim yasin karim $^{2}$, Kewan Kamal Ahmad ${ }^{3}$ and Bestun Najmadin Muhammad ${ }^{4}$.}

1. Department of Medical Microbiology, Koya University Faculty of Science and Health, Kurdistan Region-Iraq.

2. Department of Biology Collage of Science, Salahaddin University-Hawler, Kurdistan Region-Iraq.

3. Department of Biology, Koya University Faculty of Science and Health, Kurdistan Region-Iraq.

4. Directorate of Blood Transfusion Center-Erbil, Kurdistan Region-Iraq

\section{Manuscript Info}

[.........................

Manuscript History

Received: 21 November 2016

Final Accepted: 21 December 2016

Published: January 2017

Key words:-

Bacterial genetic, Laser $805 \mathrm{~nm}$, Plasmid.

\section{Abstract}

Low-intensity laser is proposed in clinical protocols based on biostimulative effects, yet dosimetry is inaccurate and their effects on DNA at therapeutic doses are controversial. The aim of this work was to evaluate the effects of low-intensity laser $805 \mathrm{~nm}$ wavelength on Escherichia coli (E. coli) and Staphylococcus aureus (S. aureus) plasmids. Our findings in this study indicate that the $805 \mathrm{~nm}$ laser has effect on gram positive and gram negative bacterial genetic profile. Studies about laser effects and safety strategies are necessary for professionals and patients exposed to low-intensity lasers at therapeutic doses.

Copy Right, IJAR, 2016,. All rights reserved.

\section{Introduction:-}

Since resistance to antibiotics is becoming an increasing problem, another possibility to battle bacterial infections are needed (Finger, et.al. 2013). Safety concerns about food, drinking water, health surveillance, and clinical diagnosis related to microbial pathogens have attracted increasing attention worldwide (Raj, et.al. 2015). Gram negative bacteria Escherichia coli (E. coli) are the leading cause of urinary tract infection, food borne illness, inflammation, bloody diarrhoea (Nataro and Kaper 1998). These are due to their ability to produce toxins and enzymes which help bacteria to avoid body immune response as well as resist antibiotic treatment (Lim, et.al. 2010). On the other hand, Staphylococcus aureus (S. aureus) is a Gram-positive spherical bacterium and it is equipped with a great variety of virulence factors, which include both structural and secreted products participating in pathogenesis of infection. In addition, it is one of the main causes of hospital and community-acquired infections which can result in serious consequences (Campanile, et.al. 2015).

Today, it is generally accepted that an exponential growth in the use of lasers has been observed in almost every area of pure and applied sciences. A wide variety of the laser propelled the invention of a several new ways research. Most of the electronic industry giants and many research laboratories are now competing to manufacture novel ranges of lasers (Nasim and Jamil, 2014). Furthermore, scientists have been agreed that the susceptibility of bacterial plasmid to laser light is varied from one Genus to another. Laser treatment has been applied for the development of an effective and safe technology for the inactivation of bacterial pathogens (Liang, et.al. 2013). It is well documented that the exposure of laser radiation was genotoxic in prokaryotic organisms also indicated that the presence of laser light selectively enhances damage on the guanine bases in DNA of pathogenic microorganism 
(Geng, et al. 2008). However, gene expression and the corresponding protein production resulting from exposure to laser radiation have not been investigated well (Raul and David, 2013).

Low-level lasers have been used among scientists to cure many diseases based on its biostimulative effect. However, the photo-biological basis for its mechanism of action and adverse effects are not well understood. The aim of this study was using experimental model to evaluate the effects of $805 \mathrm{~nm}$ laser on genetic bacterial pathogens.

\section{Materials and Methods:- \\ Bacterial isolates:-}

Two different bacteria (E.coli and S. aureus) were obtained from Teaching hospital (Erbil/Iraq). They were recultured on nutrient agar for 48 hours. Then they were cultured in nutrient broth and put them in shaking incubator for 24 hours. Identification and diagnosis for both bacteria had done by using api $20 \mathrm{E}$ system.

\section{Plasmid extraction:-}

Once the bacterial culture in nutrient broth had been prepared, we harvested the bacterial culture by centrifugation at $8000 \mathrm{rpm}$ in a micro centrifuge for 2 minutes at room temperature. Then we decant the supernatant and remove all remaining medium.

Plasmid extraction was performed by using GeneJET Plasmid Miniprep Kit for both bacteria. This methodology is based upon protocols described by manufacturer (Thermo Scientific). All extraction steps carried out at room temperature. Also all centrifugations carried out in a micro centrifuge at $12000 \mathrm{rpm}$.

\section{Gel electrophoresis:-}

Gel prepared at $0.5 \mathrm{gms}$ of powdered agarose, were mixed into $100 \mathrm{ml}$ of $1 \mathrm{X}$ TBE buffer. The mixture was then heated in microwave until it becomes clear. $1 \mu \mathrm{L}$ of Web Green was then added into the solution. The gel solution was poured into a gel tray; a comb was placed into the gel to create the wells for plasmid DNA samples. The gel was then allowed to cool and set for 30 minutes. After the mini agarose gel electrophoresis prepared, we added $10 \mu \mathrm{L}$ of the extracted plasmid DNA, with $1 \mu \mathrm{L}$ of loading dye and placed in the pores. The tray was then put in a tank containing TBE buffer. A voltage of $80 \mathrm{v} / \mathrm{cm}^{2}$ was allowed to pass through the gel for 45 minutes till the trapping dye nearly reached the edge of the gel, then examined and photographed under UV light source.

\section{Laser Device and Irradiation Setup:-}

The $805 \mathrm{~nm}$ Diode laser was used in this study with spot size diameter of $5 \mathrm{~mm}$. The exposure time was adjusted for 5,10 and 15 minutes. The setup of chopped diode laser is illustrated in Figure (1).

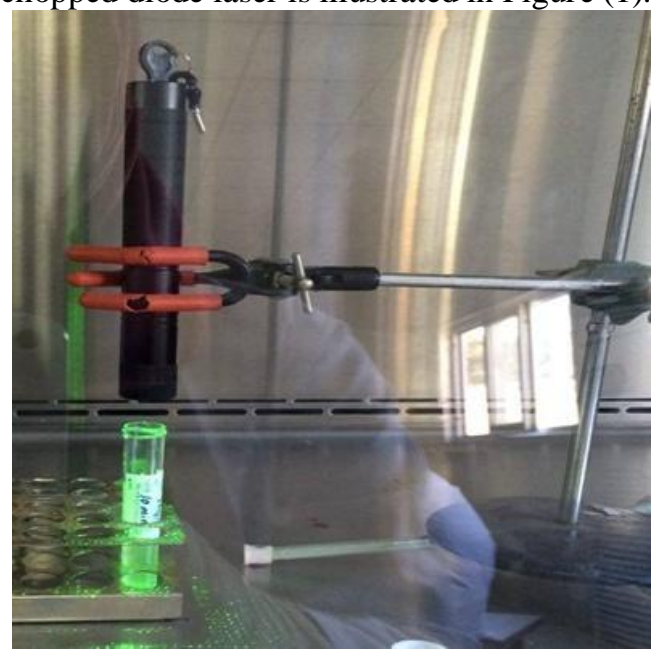

Figure 1:- laser sensitivity test shows the setup of irradiation method by Diode laser ( $805 \mathrm{~nm})$.

\section{Samples Preparation and laser Irradiation:-}

After both bacterial plasmids isolated, we added $50 \mu \mathrm{L}$ of distilled water for each of them (tubes). Then we transferred $10 \mu \mathrm{L}$ of the mixture (plasmid and distilled water) into Eppendorf tubes. The laser beam then used with the $805 \mathrm{~nm}$ wavelength, the exposure time was adjusted for three different times for both isolated plasmids which are 5,10 and 15 minutes. At the end we utilized mini agarose gel electrophoresis to study laser effect on both plasmids at different times. 


\section{Result:-}

Two different bacteria E.coli and S. aureus were selected in this study to detect the irradiation effects on their plasmid content. The irradiated DNA samples were immediately re-dissolved in $50 \mu \mathrm{l}$ of distilled water. Agarose gel electrophoresis was used to separate different forms of plasmid DNAs (irradiated and non-irradiated plasmid). The agarose gel was prepared with $0.5 \mathrm{gms}$ agarose and $1 \mu \mathrm{L}$ of Web Green; the samples were then run in the agarose gel at 80 volts for 45 minutes. The table 1 displays the loading samples into the gel. The results of the gel run are given in Figure 2, which shows the plasmid profile for both microorganisms before laser irradiation. It can be seen well number 1 represents the ladder with the size of $1 \mathrm{~kb}$. Further down in the gel, lane number 2 and 3 show the E.coli and $S$. aureus genetic profile prior to diode laser respectively. Both plasmids before irradiation in the range of above $1 \mathrm{~kb}$ in size which appears as double bands. However, the size of the E.coli plasmid(s) is bigger than S. aureus plasmid(s).

On the other hand, table 2 demonstrates the loading samples into the gel after irradiation. The consequences of the diode laser $805 \mathrm{~nm}$ on both bacterial genetic profiles as shown in figure 3 and 4 . It can be seen from the third figure that well number1, 2 and 3 contain the extracted E.coli plasmid that irradiated with 805 diode laser for 5, 10 and 15 minutes respectively. Furthermore, figure 4 demonstrates that pore number 1, 2 and 3 contain the result of irradiated $S$. aureus genetic profile in three different times 5, 10 and 15 minutes respectively. The same result for E.coli and $S$. aureus were obtained as shown in both figures (3 and 4). Thus, there is no evidence of irradiation product band for both irradiated plasmids. This is referred to the impairment of irradiation on its plasmid profile.

The molecular weights of the unknown bands were determined using a calibration curve based on the known molecular weights of the constituents of the ladder and corresponding relative distances travelled.

Table 1:- Displays well content before laser irradiation and product band sizes (bp).

\begin{tabular}{|c|c|c|}
\hline Well number & Sample type & Band size (bp) \\
\hline 1 & ladder & $1000<$ \\
\hline 2 & E.coli & $1000<$ \\
\hline 3 & S. aureus & $1000<$ \\
\hline
\end{tabular}

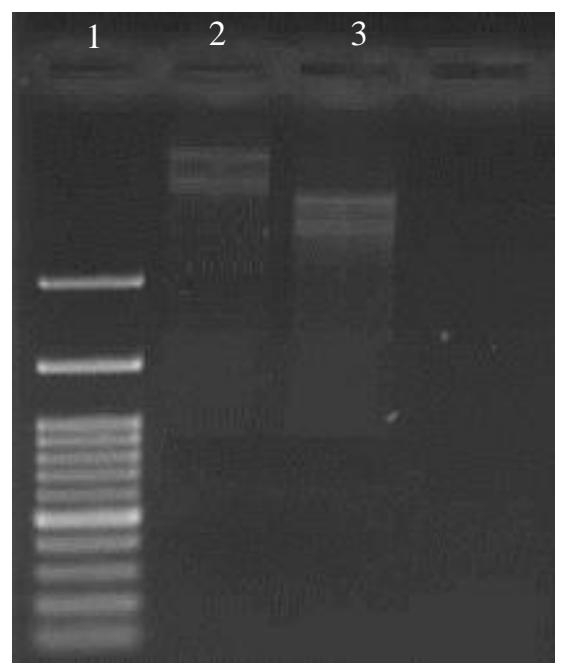

Figure 2:- Gel electrophoresis image shows well content and migration of plasmid DNA extracts before irradiation with diode laser.

Table 2:- displays well content after laser irradiation, product band sizes (bp) and time.

\begin{tabular}{|l|l|l|l|}
\hline Well number & Sample type & Band size (bp) & Time/Minutes \\
\hline 1 & E.coli & None & 5 \\
\hline 2 & E.coli & None & 10 \\
\hline 3 & E.coli & None & 15 \\
\hline
\end{tabular}




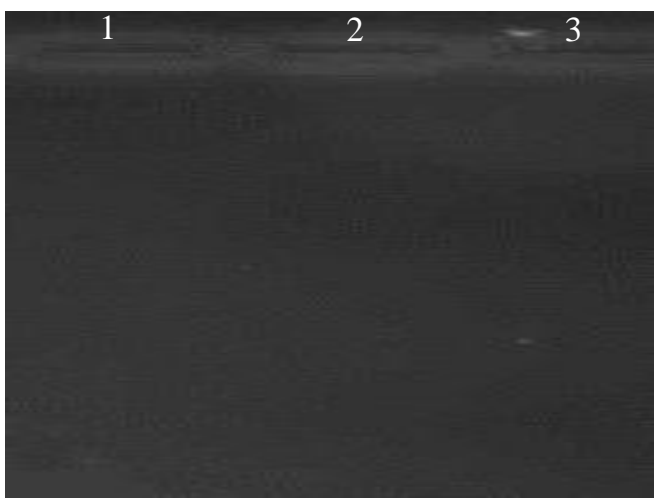

Figure 3:- Gel electrophoresis image illustrates extracted E.coli genetic profile migration after 5, 10 and 15 minutes of irradiation with $805 \mathrm{~nm}$ diode laser.

Table 3:- Displays well content after laser irradiation, product band sizes (bp) and time.

\begin{tabular}{|l|l|l|l|}
\hline Well number & Sample type & Band size (bp) & Time/Minutes \\
\hline 1 & S. aureus & None & 5 \\
\hline 2 & S. aureus & None & 10 \\
\hline 3 & S. aureus & None & 15 \\
\hline
\end{tabular}

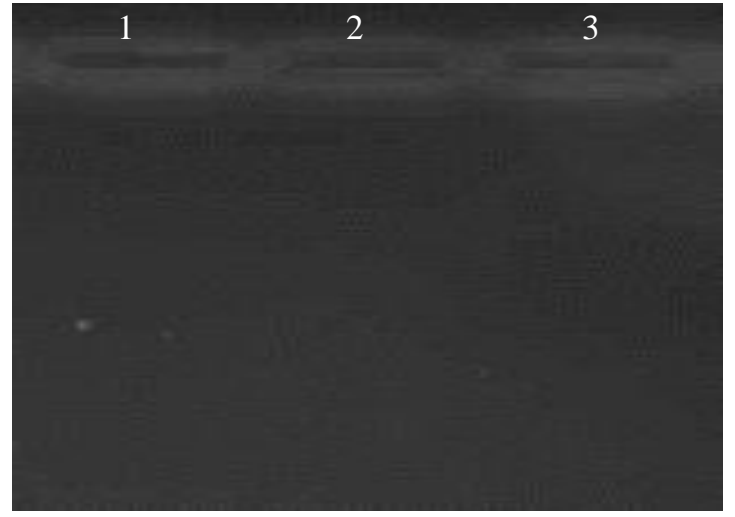

Figure 4:- Gel electrophoresis image shows isolated S. aureus plasmid migration after 5, 10 and 15 minutes of irradiation with diode laser.

\section{Discussion:-}

The problems of antibiotic resistance and pathogens in the environment are of unremitting concern for society. Traditional methods to remove and inactivate pathogens have included chlorine, UV, antibiotics, and a variety of physical and chemical processes (Capita and Alonso-Calleja, 2013, Bech, et.al. 2014). However, we are witnessing the emergence of pathogens that are resistant to these traditional methods. For example, emerging environmental pathogens such as Mycobacterium avium have been identified, which are resistant to traditional chlorine based treatments (Worley-Morse, and Gunsch 2015). Furthermore, antibiotics are no longer as effective due to the emergence of multiple types of antibiotic resistance, and there is concern of entering a post-antibiotic era. Clearly, there is a need to investigate alternative disinfection strategies for controlling pathogens in the environment and in engineered waste streams.

One novel approach to controlling environmental pathogens is the use of laser, which has received much attention in the medical field as a way to specifically damage plasmid DNA by disabling the antibiotic resistant gene.

We have investigated laser-induced DNA strand breaks in plasmids. The supercoiled plasmid was irradiated at $805 \mathrm{~nm}$ wavelength. The plasmid may exist in supercoiled, relaxed-circular or linear conformation. Only one single strand break (SSB) is sufficient to relax DNA in supercoiled form to relaxed-circular form. One double strand break (DSB) will produce linear molecules (Adjei, et.al. 2016). 
Generally, this study shows that the laser $805 \mathrm{~nm}$ irradiation had a major effect on E.coli and S. aureus plasmids. he idea of inducing DNA cut photo chemically has attracted attention, the strand breaks of plasmid DNA might be due to singlet oxygen that is generated through the irradiation process which causes bacterial genetic profile to be cleaved due to the interaction with nitrogen base of DNA especially guanine bases which might be act as sinks for electrons holes within DNA owing to their propensity to be oxidized. The electron holes induced by laser irradiation may be propagated via stacking interactions in the DNA helix until it encounters guanine cluster, where it may persist longer than at other sites (Sies, et.al.1996, Adjei, et.al. 2016)

\section{Conclusions:-}

In conclusion, we have demonstrated the possibility and advantages of using $805 \mathrm{~nm}$ laser. Bacterial plasmid(s) could be impaired by laser irradiation for instance E.coli and S. aureus plasmids. This means that many antibiotics could be replaced by diode laser $805 \mathrm{~nm}$ wavelength for curing infectious microorganisms. Overall, it is believed that the diode laser $805 \mathrm{~nm}$ wavelength can meet the scientist's challenges from laboratories to industries.

\section{Reference:-}

1. Finger, S., Wiegand, C., Buschmann, H., Hipler, U. (2013) Antibacterial properties of cyclodextrin-antisepticscomplexes determined by micro plate laser nephelometry and ATP bioluminescence assay. International Journal of Pharmaceutics. 452. pp188- 193.

2. Raj, V., Vijayan, A. N., Joseph, K. (2015) Cysteine capped gold nanoparticles for naked eye detection of E. coli bacteria in UTI patients. Sensing and Bio-Sensing Research. 5. pp33-36.

3. Nataro, J. P., and Kaper, J. B. (1998) Diarrheagenic Escherichia coli. Clin Microbiol Rev. 11(1): pp142-201.

4. Lim, J. Y., Yoon.J. W., and Hovde. C. J. (2010) A Brief Overview of Escherichia coli O157:H7 and Its Plasmid O157._J Microbiol Biotechnol. 20(1). pp5-14.

5. Campanile, F., Bongiorno, D., Perez, M., Mongelli, G., Sessa, L., Benvenuto, S., Gona, F., Varaldo, P. E., Stefani, S. (2015) Epidemiology of Staphylococcus aureus in Italy: First nationwide survey, 2012. Journal of Global Antimicrobial Resistance. 3. pp247-254.

6. Geng, J., Yu, S., Wan, X., Wang, X., Shen, P., Zhou, P., Chen, X. (2008) Protective action of bacterial melanin against DNA damage in full UV spectrums by a sensitive plasmid-based noncellular system. J. Biochem. Biophys. 70. pp 1151-1155.

7. Bech, T. B., Rosenbom, A. E., Kjaer, J., Mostofa Amin, M. G., Olsen, P., Jacobsen, C. S. (2014) Factors influencing the survival and leaching of tetracycline-resistant bacteria and Escherichia coli through structured agricultural fields. Agriculture, Ecosystems and Environment. 195. pp10-17.

8. Capita, R., Alonso-Calleja, C., (2013) Antibiotic-resistant bacteria: a challenge for the food industry. Crit Rev Food Sci Nutr. 53 (1). pp11-48.

9. Cueroa, R., and McKay, D. S. (2013) Induction and construct UV protective yeast plasmid. Journal of Biotechnology. 166. pp76-83.

10. Liang, J., Yuann, J. P., Cheng, C., Jian, H., Lin, C., Chen, L. (2013) Blue light induced free radicals from riboflavin on E. coli DNA damage. Journal of Photochemistry and Photobiology B: Biology. 119. pp60-64.

11. Nasim, H., and Jamil, Y. (2014) Diode lasers: From laboratory to industry. Optics \& LaserTechnology. 56. pp211-222.

12. Worley-Morse, T. O., and Gunsch, C. K. (2015) A computational analysis of antisense off-targets in prokaryotic organisms. Genomics. 105. pp123-130.

13. Adjei, D., Wiechec, A., Wachulak, P., Ayele, M. G., Lekki, J., Kwiatek, W. M., Bartnik, A., Davídková, M., Vyšín, L., Juha, L., Pina, L., and Fiedorowicz, H. (2016) DNAstrandbreaksinducedbysoftXraypulsesfromacompactlaser plasma source. Radiation PhysicsandChemistry. 120. pp17-25.

14. Sies, H., Schulz, W. A., and Steenken, S. (1996) Adjacent guanines as preferred sites for strand breaks in plasmid DNA irradiated with $193 \mathrm{~nm}$ and $248 \mathrm{~nm}$ UV laser light. Journal of Photochemistry and Photobiology. 32. pp 97-102. 